\title{
Putting Interference to Work in the Design of a Whole-class Learning Activity
}

\author{
Tom Moher \\ Department of Computer Science \\ Institute for the Learning Sciences \\ University of Illinois at Chicago, Chicago, IL, USA \\ $+1.312 .996 .4562$ \\ moher@uic.edu
}

\begin{abstract}
Who's Who is a single-display groupware application designed for use by an entire class of young students. Utilizing a shared display, each user controls the state of discrete display elements using a simple interface on a handheld device; however, the semantics of user operations are left unspecified and become the subjects of guided student discovery. Interference among users is leveraged in support of student learning about the scientific principle of "control of variables," in particular, the strategy of varying one independent variable at a time in multivariate systems. We present the experience of a third-grade classroom that used Who's Who, including both an account of learning outcomes and a description of the technology and social interactions that led to those outcomes.
\end{abstract}

\section{Categories and Subject Descriptors}

D.3.3 [Computers and Education]: Computer Uses in Education - collaborative learning

\section{General Terms}

Design, Human Factors

\section{Keywords}

Interference, single-display groupware, control of variables, science inquiry, elementary school learners

\section{INTRODUCTION}

Over the course of a day, most classrooms offer a variety of activity structures. Sometimes students work individually, solving math problems or writing compositions. Sometimes they work in small groups, analyzing problems or creating shared artifacts. But most often, even in the most progressive classrooms, activity is organized to engage the class as a whole, particularly for younger children [18]. As a practical matter, the management burden inherent in activities that partition classes can be daunting for teachers; whole-class activities allow teachers to communicate and monitor student behavior efficiently. Moreover, whole-class activity designs provide forums for learners to develop communication skills among larger audiences of their peers.

Permission to make digital or hard copies of all or part of this work for personal or classroom use is granted without fee provided that copies are not made or distributed for profit or commercial advantage and that copies bear this notice and the full citation on the first page. To copy otherwise, or republish, to post on servers or to redistribute to lists, requires prior specific permission and/or a fee.

IDC 2009, June 3-5, 2009, Como, Italy

Copyright 2009 ACM 978-1-60558-395-2/09/06 ... \$5.00.
Among these three categories, individual and small group activities have been the subjects of central focus among developers of learning technologies. The conceptions of computers as individual resources dominated the early visions of classroom technology, and continue to play an important role with the maturation of intelligent tutoring systems (e.g., [11]) and the growth of inexpensive and portable computing platforms [12]. At the same time, the virtues of collocated collaborative learning activities have generated a great deal of interest and research around technology platforms such as shared displays and tabletop interfaces that support a handful of students concurrently.

The increasingly ubiquitous classroom video projector-the "high tech" successor to the overhead projector-has emerged as the dominant technology supporting whole class activities. As important as this technology has proven, however, it almost necessarily relegates students to relatively passive roles within a transmissive learning paradigm. With some exceptions (e.g., $[8,19])$, it has proven relatively difficult for designers to envision ways to deploy technology that could support a whole-class collaborative task while still affording the kinds of individual interaction opportunities that are likely to raise student engagement and promote active learning.

One roadblock to the design of whole-class technologies has been the interference associated with collocated group interfaces. Even among technologies designed to support relatively small groups of users, contention for input devices and interface artifacts, or the semantic interdependence among user actions (e.g., one user's decision limiting or undoing the actions of other users) imposes significant design constraints. As a consequence, much of the research surrounding the development of such systems has focused on mechanisms for enforcing turn-taking [5], or on precluding interference by partitioning the interaction space in ways that eliminate or reduce interference (e.g., [3,17]).

And yet, interference, while a design challenge, is also a necessary and important element of much of human activity, and learning to deal with interference-whether contention for the last seat on the subway train or finding a new route around a closed highway-is an important goal in its own right. Hornecker, et al., for example, argue that, even within work environments, the negotiation of control arising from interference may play a productive role in task coordination [4].

In the domain of scientific investigation, the management of interference plays a central role, and the development of strategies for controlling extraneous factors when conducting experiments is well represented in standards and curricula for young learners $[1,10]$. The control of variables $(\mathrm{CoV})$ strategy is not easy to 
master, particularly across content domains; even college-aged students show unreliable application of the strategy $[7,13]$. However, successful instructional strategies have been developed for even young children. Chen and Klahr [2] demonstrated that children in second through fourth grades could be successful at adopting the CoV strategy given a combination of (1) opportunities to design their own experiments and (2) direct instruction in the design of unconfounded experiments.

In this paper, we describe a whole-class, single-display groupware [16] application, Who's Who [9], in which interference serves not only as a prompt for negotiation, but as a condition sine qua non for the designed learning activity. In Who's Who, interference among users is directly aligned with confounding among independent variables in a multivariate system; solving the instructional challenge requires the guided discovery and application of the CoV strategy of varying one thing at a time. Along the way, it also entails practice in the articulation and testing of hypotheses and the design of collaboration strategies.

\section{WHO'S WHO}

The interface to Who's Who includes two components: a single shared display that is projected in front of a whole class, and individual wireless handheld devices that students employ to interact with the system. The main portion of the shared display depicts a two-dimensional grid consisting of a number of large colored circles, with each colored circle initially shaded either blue or orange (Fig. 1). In the lower right-hand corner of the display is a small picture of the goal state of the activity; in this case, a configuration in which all of the circles are shaded blue. A digital clock provides feedback to the students on the elapsed time they have spent on the activity; students are asked to move from the initial state to the goal state as quickly as possible.

The individual handheld devices contain a simple interface consisting of a single large button (Fig. 2). Each handheld is associated with a single colored circle on the display; touching the button on the handheld causes that circle to toggle between the orange and blue shading. A laptop computer serves as the wireless server for the handhelds and generates the image displayed by the video projector.

The challenge in the activity arises from the fact that the students are given minimal information; they are simply charged to reach the goal state. Implicitly, they understand that they have the power to effect state changes, and that the handhelds are the vehicles by which they can achieve their goal. However, they are informed of neither the 1-to-1 mapping between their individual devices and the display, nor of the semantics of the button presses; both remain to be discovered as part of the activity.

In order to meet the objective of the activity, the students need to address three issues. First, they must come to an understanding of the mechanism underlying the application, that is, the 1-to-1 correspondence between the colored circles and the handhelds, and the effect of touching the buttons. Second, they must collectively invent a strategy - here, the CoV strategy of varying inputs one at a time- that will allow them to reach the goal state. Finally, they must develop a self-regulating social process that will allow them to systematically implement their strategy.

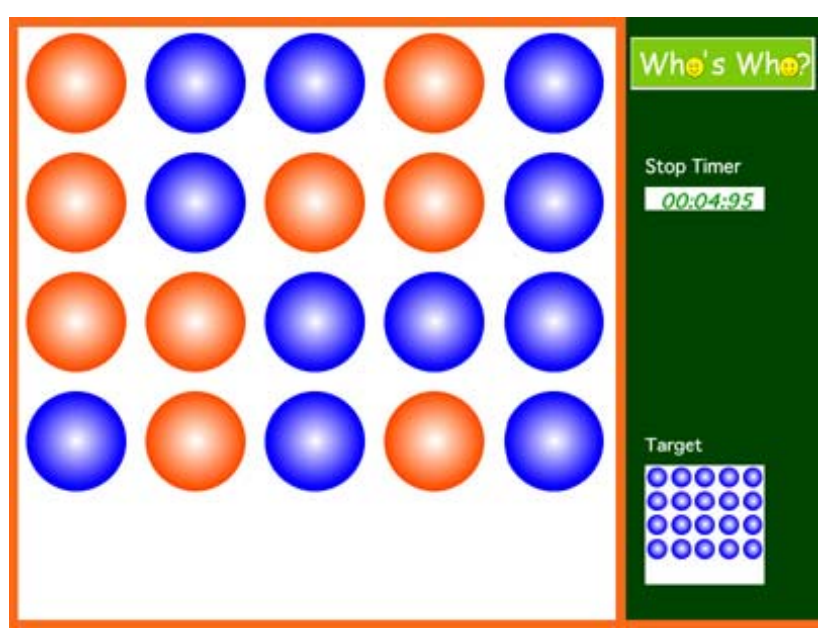

Figure 1. Interface to Who's Who shared display. Colors of large circles toggle in response to button press on handheld.

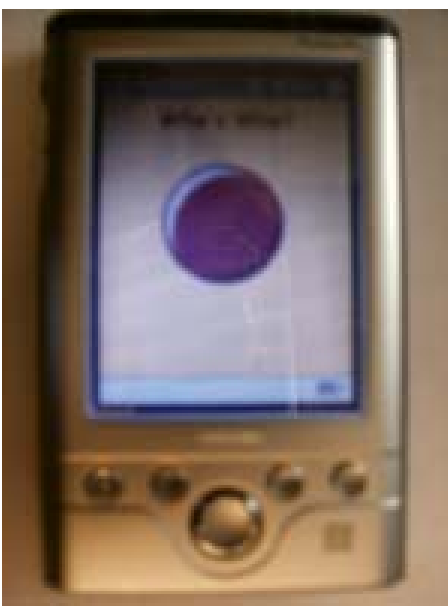

Figure 2. Handheld interface to the Who's Who activity.

\section{AN EMPIRICAL STUDY OF STUDENT LEARNING}

We conducted an empirical study to gain some insight into the ways that young learners would make sense of Who's Who, while at the same time developing some evidence regarding its potential effectiveness in their development of the one at a time $\mathrm{CoV}$ strategy. It was not clear at the outset that either would be within the capabilities of young learners; we were concerned that they might give up without coming to an understanding of how the software worked, that they might fail to develop a strategy for solving the problem, and especially that, even if they composed a plan, the task of organizing themselves to implement the solution might prove overly arduous. We also expected that multiple iterations of the activity would be required in order for the students to develop and exercise their emergent understandings.

\subsection{Method}


Twenty third-grade children (age 8-9 years) in an intact classroom, including eight girls and nine boys, participated in the activities; of these, 17 students completed all phases of the study. Each child was given a written pre-test to evaluate his or her understanding of the $\mathrm{CoV}$ strategy in an alternative domain: articulation of an effective strategy for determining which of three ingredients in a mixture of dog food caused the dog to refuse to eat. The whole class participated in the Who's Who activity on two consecutive days, sitting on the floor in front of the projected display, with different handheld-to-circle mappings used on each day (Figure 3). Each child was interviewed following each of the two sessions to probe his or her understandings of the mechanism and (task-specific) strategy arising from the preceding session. The canine diet preference assessment was administered again following a three-week delay to test the learners' CoV concept retention and ability to transfer their understandings to a new domain.

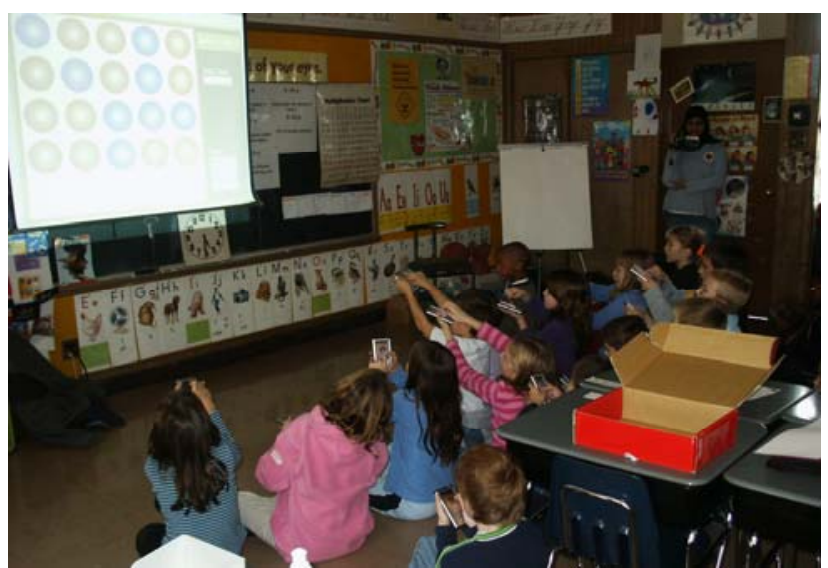

Figure 3. Students use handhelds to control shared display.

\subsection{Data Sources}

In addition to the pre- and post-tests, an event log of button presses was maintained at the server, and both the Who's Who sessions and interviews were videotaped. During the 10-20 minute interviews, students were asked a series of 19 questions designed to probe their understanding in the three problem-solving areas: the mechanism of operation, strategies for implementing control of variables, and the social processes used to effect a solution. Following the pilot activities, each video was reviewed and responses were coded using a group consensus process. In assessing their understanding of mechanism, students were rated on a six point scale, with one point each awarded for evidence of the child's understanding that (a) their button affected the display, (b) their button controlled an individual circle, (c) pressing the button toggled a circle's color, (d) button presses were the only factors which controlled the image, (e) everyone's button worked in a similar fashion, and (f) the class collectively controlled the entire display. The CoV strategy was ranked on a five-point scale, with one point each awarded for (a) articulation of a "one at a time" strategy with respect to pairs of students, (b) articulation of the same strategy with respect to the whole class, (c) articulation of the negative implications of simultaneous clicks with respect to achieving the goal, (d) explanation of why the task would be equally difficult whether the goal state was "all blue" or "all orange" colored circles, and (e) ability to recall an ineffective strategy that arose during the Who's Who activity and explain the reason for its failure. Performance on the pre- and post-tests were assessed on a binary scale, with responses judged correct if the student articulated a strategy that involved feeding the dog one ingredient at a time to see whether the dog refused to eat that ingredient (Fig. 4).

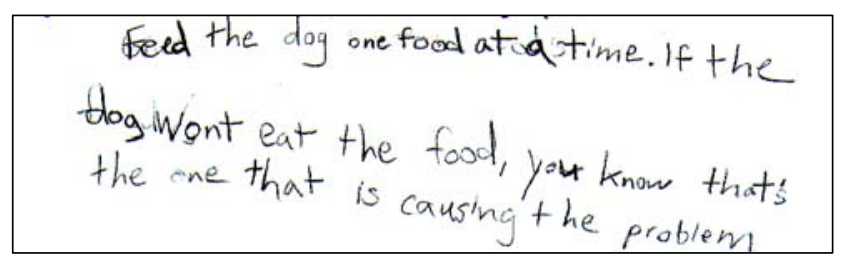

Figure 4. Student response judged "correct" in pre-post transfer question regarding canine food preferences.

\subsection{Results}

Task completion. The children succeeded in reaching the goal state in both activity sessions; however, the contrast between the two was dramatic. In the first session, 32.5 minutes were required to complete the task, while the second session lasted only 3.9 minutes.

Interaction. Students averaged 490 button presses during the first activity, or one press about every five seconds. Individual students ranged from 147 to 939 presses. While activity was especially frenetic during the first few minutes, the rate of activity declined over time as the children progressed toward a solution. Girls averaged 574 presses to the boys' 406; due to the high variance, however, the difference was only marginally significant $(\mathrm{p}=.11)$ on a two-tailed $t$ test.

During the second session, students averaged 11 button presses, or about one press every 20 seconds, a significantly lower activity rate than during the first session. Four of the students pressed the button the minimum number of times (either once or twice, depending on the initial state of their pixel) required to contribute to the solution; only two students pressed their buttons more than 20 times. Boys and girls each averaged 12 button presses. The number of button presses during the first session was not a predictor of activity during the second session $\left(\mathrm{R}^{2}=.04\right)$.

Students learned to control the handhelds in ways that were responsive to changes the task. Initially, button presses represented micro-experiments designed to uncover the system mechanism, and more experiments meant more potential information. Once discovered, button presses became purposeful, and the usage pattern changed appropriately.

Strategy understanding. Performing Who's Who a second time did not improve students' understanding of the "one at a time" strategy. On the five-point scale of strategy understanding, students averaged $4.53(s=0.71)$ and $4.47(s=0.62)$, respectively, following the two sessions, $t(16)=0.37$, n.s.

Mechanism understanding. In contrast, a second round of the activity did have a substantial impact on students' ability to explain the system mechanism. On the six-point scale of mechanism understanding, students averaged $3.71(s=1.49)$ and $5.12(s=1.11)$ points, respectively, following the two sessions, $t(16)=3.59, \mathrm{p}<.01$.

Task-directed discourse. While conversation ebbed and flowed, on average students devoted a higher proportion of their discourse (relative to off-task discussion) as the activity proceeded, 
supporting a claim that the learners were engaged in the task. Elapsed time significantly predicted proportion of goal-oriented discourse, $\mathrm{b}=.014, \mathrm{t}(30)=3.80, \mathrm{p}<.01$. Elapsed time also explained a significant proportion of variance in proportion of task-oriented discourse, $\mathrm{R}^{2}=.32, \mathrm{~F}(1,30)=14.46, \mathrm{p}<.01$.

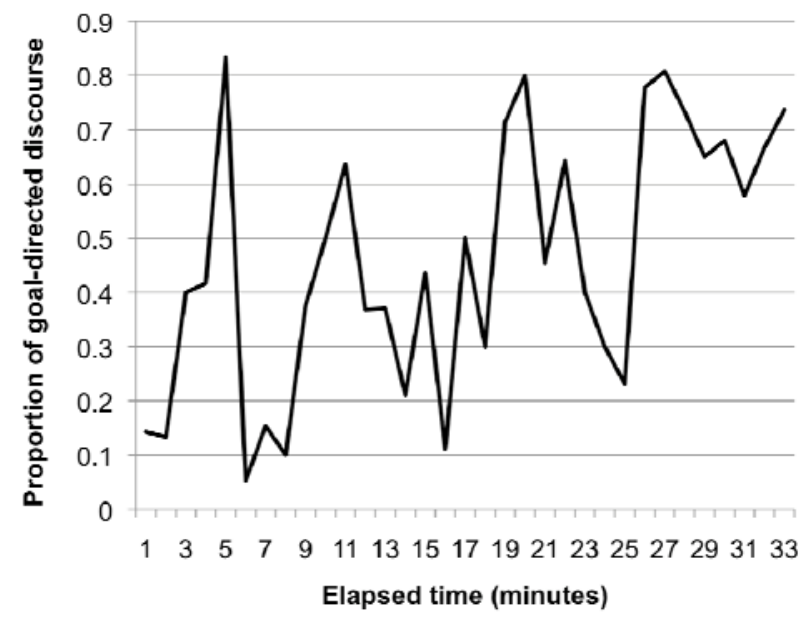

Figure 5. Proportion of goal-directed discourse over time during first Who's Who session.

Transfer. Student ability to articulate the "one at a time" $\mathrm{CoV}$ strategy improved significantly from pre- to post-test $\left(\chi^{2}(1)=5.1\right.$, $\mathrm{p}<.03$ ), from $53 \%$ on the pre-test to $88 \%$ on the delayed post-test.

\section{BEHIND THE NUMBERS}

The first session of Who's Who unfolded in two distinctive segments, with a critical "pivot" occurring around 20 minutes into the session. The first segment was devoted to understanding the mechanism underlying the technology suite, with student suggesting, and testing, a number of hypotheses regarding the relationship between the handhelds and the shared display. The critical "pivot" involved the articulation — and group acceptanceof an explanation of the mechanism. During the second segment, the students used their understanding of how the system worked to devise and implement a plan for reaching the task objective. (Figure 7, on the following page, offers a graphical representation of the flow of discourse based on transcription of student comments during the first episode of Who's Who).

\section{Segment 1: Discovering the Mechanism}

Pointing. The third grade students were active in offering hypotheses regarding system functionality. They saw quickly that the "action" on the screen consisted of changes in the colors of the circles, and that there were only two colors: orange and blue. Apparent from the beginning was their expectation, likely borne

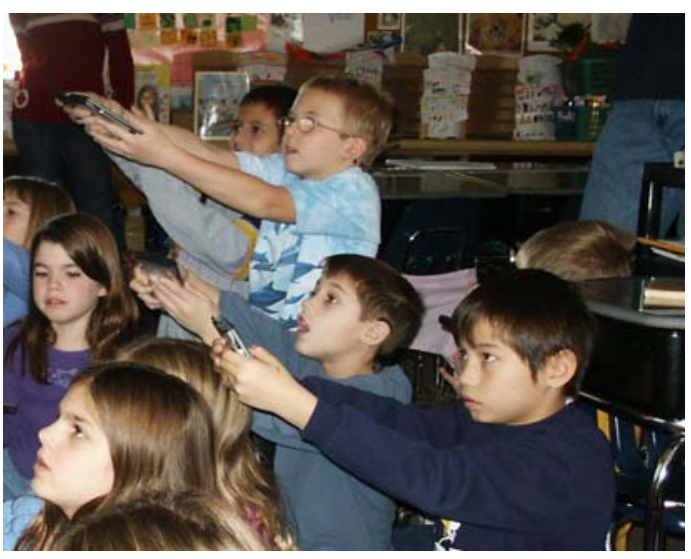

Figure 6. Students “aiming” handheld devices at circles on shared display.

of experience with infrared remote controls, that there was a relationship between where they "aimed" their handheld devices and individual colored circles (Fig. 6); operation of the handhelds was often done "at arm's length" with careful attention to alignment. The belief in the "pointing" hypothesis was especially strong around five minutes into the activity, but was (at least temporarily) rejected when one student walked up directly in front of the display ("get up close") and pointed his handheld at a colored circle at a distance of about one inch. While the hypothesis about the need to point at an individual circle in order to change its color was largely abandoned at this point, children continued to believe that pointing in the general direction of the display was necessary in order for the button presses to have an impact.

Simultaneity. At approximately nine minutes into the activity, one student raised the hypothesis that if all of the students were to simultaneously press their buttons, all of the colored circles would turn blue. This suggestion was met with enthusiasm among the students, who attempted several synchronized ("Okay, $1 . .2$...3...go") button presses by all of the class members. The hypothesis was abandoned when the action failed to cause the desired effect; a subsequent attempt to re-raise the hypothesis four minutes later was dismissed ("No, that doesn't work. We tried that already.") and never again arose during the activity.

Position. By about ten minutes into the activity, there appeared to be an emerging sense regarding a potential 1-to-1 relationship between the handhelds and the colored circles. One student noticed that a label with a number printed on it was attached to the back of her handheld, and suggested, "It might make it easier if we could, um, line up the kids in the same way that the circles are lined up." (In fact, the labels were simply inventory tags, and had no relationship to the handheld-to-circle mappings.) A brief discussion followed, but the students found it difficult to find a way to map the ordinal tags to the two-dimensional image on the display. The "position" hypothesis was never again raised during the activity. 


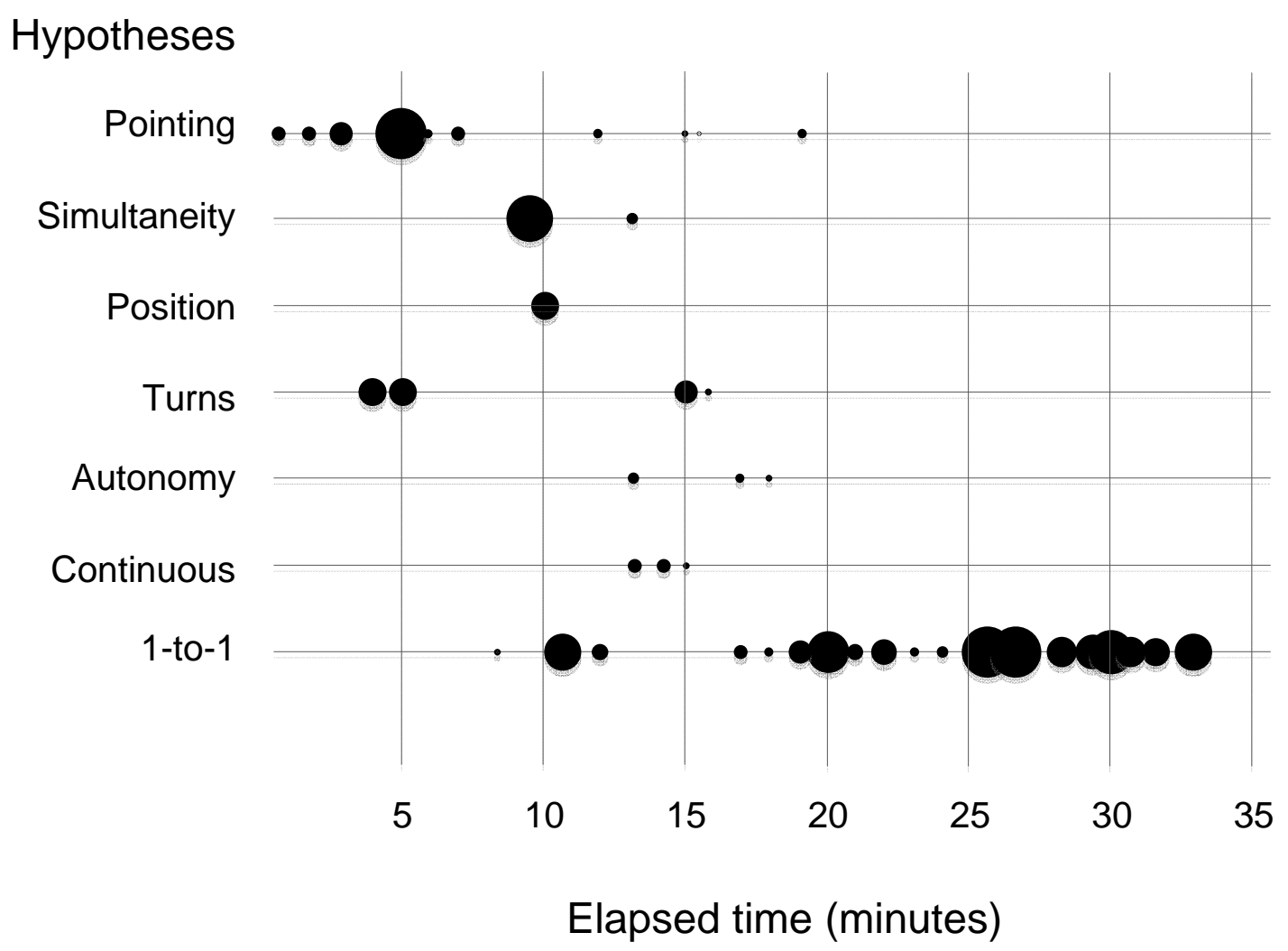

Figure 7. Distribution of student verbalizations by hypothesis thread over time. Circle diameters are proportional to number of verbal comments. Read across to follow trajectory of hypotheses, and read down to see the distribution of discourse among hypotheses over time.

1-to-1 (normative). At 11 minutes into the session, the notion of an individual, 1-to-1 "ownership" of circles began to be explored, triggered by one student's observation that "there are the same number of circles as there are kids.” At this point, however, the students didn't know how to make use of the information, because they were not yet able to find a way to establish a method for determining which circle "belonged" to which child. While this episode represented a "false start" toward a solution, it provided as a critical piece of the puzzle.

Continuous pressing. Somewhat discouraged at their lack of progress, the next few minutes saw the emergence of hypotheses that, while not directly challenging the 1-to- 1 mapping, were at least orthogonal to it. Minute 13 focused on an hypothesis raised by one child that if all the students touched the buttons on the handhelds and held them down continuously (rather than releasing them) that the circles would all turn blue; this harkened back to the "simultaneity" hypothesis explored a few minutes earlier. As earlier, a synchronized experiment failed to produce the desired result, and this hypothesis, too, was abandoned.
Autonomy. Increasingly frustrated, some students began to wonder whether the circles were changing colors independent of the button presses on the handhelds ("are these moving by themselves?"). One student immediately recognized an experiment that could test this hypothesis, loudly suggesting, "okay, everybody stop.” Not unexpectedly, this proved difficult to enforce in a group of 20 third grade students; while most students stopped, several students continued to press their buttons, some rather surreptitiously. Because it was difficult for the students to monitor each others' actions, some students began to conclude that "they are changing colors by themselves." At this point, the teacher reminded them that they had defined a plan, but that they weren't implementing it. After another minute or so, reinforced by peer pressure, all button presses halted, and the children agreed that spontaneous color changes were not taking place.

\subsection{Pivot Point}

At 19 minutes into the activity a child who had been relatively quiet throughout the discussion made a critical observation. In spite of the visual "noise" created by the colors changing on the 
screen, he had carefully timed his button presses and noticed that his actions seemed to consistently toggle the color of one specific circle, "I know what it is. Whenever I press this, my button, that one [circle] between those two [circles] turns...so it's like we all have our own dot." This observation, the first explicit articulation of the 1-to-1 mapping between handhelds and circles, successfully linked the understanding that the number of circles and kids was the same and a method (albeit a challenging one) of identifying which circle belonged to which child. His observation met with immediate reinforcement from several other students, who also began to identify circles that they considered "their own."

\subsection{Segment 2: Developing and Implementing a Solution Strategy}

Developing a strategy. The mechanism now clearly established, at approximately 20 minutes into the activity students began to suggest methods of determining, for those who didn't know yet, which circle was "theirs." One student proposed that everyone synchronize their button presses to resolve the mapping; this suggestion was implemented, but provided the students with no additional information. Another student suggested that "only press your button if your dot is orange," but there were still many students in the class who didn't know which circle their handheld corresponded to.

At this point, several students began to recognize that in order to complete the activity, it would be necessary to find the "owners" of the remaining orange circles, and there were multiple calls for everyone to stop pressing buttons so that individuals could test their buttons "one at a time."

Implementing the strategy. The final seven minutes of the activity were devoted to implementing the strategy that the students had collectively established. As before, achieving the goal of having "everyone stop" proved challenging, and the teacher needed to again remind the students of their collective decision to implement their strategy and their responsibility to one another to see it through. Once the regimen had been established, however, the class saw that it was effective; by stopping and having one student at a time press their buttons, they began to reduce the number of remaining orange circles and develop a strong sense of progress toward their goal. This provided social reinforcement for the process, and the students moved quickly toward the solution, which was met by a loud collective cheer.

\subsection{Session 2: Skilled Execution of a Solution Strategy}

The second session with Who's Who surprised us with its brevity and efficiency. Although the handhelds were now mapped to different circles on the screen, the children almost immediately imposed a "stop everything" regimen upon themselves and systematically asked each student to push their buttons one at a time, noting the effect and asking for remedial action if a circle turned orange rather than blue. While there was pride in accomplishing the task quickly, the euphoria of the previous day was no longer there; the task had become routine.

\section{DISCUSSION}

Who's Who proved to be a challenging activity for the third grade students, but one that was, in the context of social scaffolding provided by the classroom teacher, ultimately within their grasp.

\subsection{Learning Outcomes}

What did the children gain from the experience? At least at a very primitive level, the students appeared to gain some facility with the $\mathrm{CoV}$ strategy of varying one independent variable at a time. We saw evidence of this facility at an aggregate level in their articulation and implementation of this strategy within the Who's Who activities, and individually in their accounts of the strategy in post-activity interviews and improved ability to apply their understanding of the strategy within a different domain. The prepost assessment that we employed demanded only the simplest characterization of the strategy, and repeated measures assessments are necessarily subject to concerns that the repetition of the assessment might influence performance. Nonetheless, taken as a whole, we believe that the students in this class evidenced limited but real conceptual gains.

There is no evidence here that this was the "best" way for them to learn the "one at a time" strategy, nor was it our goal to present such evidence. The students might have performed equally well on the pre-post assessment with intervening direct instruction [6], or with a more structured inquiry design. But we believe that there were benefits to the children that extended beyond the understanding of the CoV strategy. The video record of the activity leaves little doubt concerning the children's active engagement or their sense of accomplishment upon solving the problem. The activity gave them an opportunity to present and respond to hypotheses within the social context of their peers, and to design and exercise experiments to test those hypotheses. More broadly, the activity created a context within which a high degree of collaboration was essential.

The mechanism hypotheses raised by the students drew from their prior experience, and were both imaginative and enlightening. Of particular note are the hypotheses that presumed the mechanism to be based on "trickery," as in the "simultaneous button press" and "spontaneous color change" hypotheses. On the one hand, it is sobering to realize that the children expected we might introduce such mechanisms, or that their experiences (for instance, with the kinds of "arbitrary" interactions that might be effective in video games) might lead them to look for such shortcuts. On the other hand, from the kids' perspectives, such affordances might seem no more capricious than the mechanism, certainly outside their experience, that they actually encountered; to third graders, they were, perhaps, equally likely technological magical incantations.

In terms of group task performance time, the improvement between the two sessions was especially dramatic. One possibility is that the solution strategy was relatively difficult for the students to devise and implement, but once accomplished, replication was easy. We believe that this was certainly an important contributing factor, but not the whole story. Our strong suspicion is that if the students had conducted the second session immediately after the first session, the performance time would have improved, but not nearly by the margin that occurred in this case. More important, we believe, were the interviews that we conducted with the children. While the interviews did not introduce new information to the students, nor endorse or critique proposed solutions, they did provide the children with an extended opportunity to reflect on their experience, and to verbalize their solution strategies. Once rehearsed, it was easier for (at least some) students to articulate those strategies when placed back in a whole-class setting. 
From the perspective of individual learners, the second session had no impact on their ability to articulate the CoV strategy, but did allow some students to get a stronger handle on system mechanics. We saw this particularly in their improved understanding of the 1-to-1 relationship between handhelds and the display circles, and in the lack of autonomous color changes unassociated with button presses, both of which were more prevalent in the interview following the first session. Apparently even the relatively short second session with their peers (and a second opportunity to reflect during the subsequent interview) was sufficient to resolve these issues to their satisfaction.

\subsection{Social Interaction}

While it is always problematic to generalize from such a small sample, at least in this instance, with this group of children, gender aligned fairly strongly with role in the problem-solving aspects of the activity. The boys in the classroom were especially active during the initial mechanism discovery segment of the first session, literally shouting out hypotheses and critiques with regularity. This is not to say that the girls were passive; their greater level of interaction with the handhelds indicated that they were actively, if less vocally, exploring hypotheses on their own. Once the critical pivot had been made, however, and the activity turned to the identification and enactment of a process to achieve the goal, the girls assumed the leading role. In the second session, with the mechanism already well established, the girls entirely ran the show.

Whole class activities such as this necessarily reflect underlying social relationships and hierarchies. During our interviews, we asked students to name classmates who they felt had played leadership roles in solving the problem. Excluding self-references, nine of the 20 students were named as playing key roles during the first activity, with two students - characterized by the teacher as social leaders of the class-were mentioned at least twice as often as any other children. A review of the videotapes of the activity revealed that while those two did participate in the discussion, neither played an especially prominent role in defining system mechanics or a strategy for solving the problem, but instead reiterated suggestions first proposed by others. In contrast, another student-with a reputation as the "class clown"-who was the first to suggest the 1-to-1 relationship between handhelds and display circles, failed to receive credit for his contribution among his peers.

It is important to underscore the active role of the classroom teacher in the Who's Who lesson; indeed, it is impossible to imagine that the students would have achieved their goal, or developed their understandings, without adult scaffolding and guidance. In the midst of the apparent chaos, the teacher played a critical role far beyond crowd management, actively eliciting and highlighting student hypotheses, reminding students of hypotheses that were "on the table" awaiting experimentation, and helping students to consolidate and articulate their discoveries in ways that were useful to their peers.

\subsection{Technology}

Who's Who is a "one-off" application in the sense that it was designed to support a single activity. While the students gained in their mechanism understanding by using Who's Who a second time, there would have been little to gain by a third round. It would, of course, be possible to invent other activities using the same technologies by simply changing the relationship between user actions (button presses) and their effect on the display. For example, introducing a latency between action and result, varying the handheld-to-display mapping over time, or dropping the 1-to-1 relationship so that handheld actions impact more than a single display circle-all of these are easily programmed, and it is possible to imagine (carefully scaffolded) learning activities built around such mechanisms. However, it would be easy to create activities that were either too difficult to solve or involved arbitrary "tricks" unlikely to be discovered by learners.

Nonetheless, the "form factor" represented by Who's Whowireless transmission combined with an extremely simple button interface-may warrant additional consideration by designers. Commercially available audience response systems (ARS) offer an inexpensive platform for such applications, and some companies are now offering software development kits to third party developers. While the canonical use of these systems has involved (more or less) synchronous polling, the transmitters are small and portable, and transmit not only the user response but also the user identity, leaving open the possibility of creating applications tracking time-stamped asynchronous activity, in the aggregate or by the individual. (It is this latter capability, for example, that could enable an ARS-based version of Who's Who.) We are in the early stages of designing prototype applications using these technologies to support novel learning activities, formative assessment, and process data capture.

\section{CONCLUSION}

From the perspective of interaction design, one of the strengths of Who's Who is the combination of a high degree of technology interaction within the context of peer discussion and debate. The activity is an extreme exemplar of a "jigsaw" cooperative learning design, with a high degree of interdependence among all the children and a binary task outcome demanding the full cooperation of every member of the class [14]. The simplicity of the interface sets a low bar for entrée into the activity, and even the least active (technology) participant was interacting with their device approximately every 15 seconds. Who's Who, we believe, was successful in keeping both hands and minds busy in a way that didactic instruction or strictly personal technological designs might not have afforded.

Finally, Who's Who serves as case study of a way in which we are sometimes able to turn a phenomenon (in this case, interference) that is seen as problematic in some contexts to our advantage in the design of learning activities. Designing for learning remains a distinct craft from designing for usability [15], and, as is often the case, what makes an activity hard is the very thing that makes it both effective and-not to be discountedwhat makes it fun.

\section{ACKNOWLEDGMENTS}

Thanks to Xun Ding for developing the Who's Who application, and to Jennifer Wiley for guiding me to the research on learning and the control of variables.

\section{REFERENCES}

[1] American Association for the Advancement of Science. 1993. Project 2061: Benchmarks for science literacy. New York: Oxford University Press.

[2] Chen, Z. and Klahr, D. 1999. All other things being equal: Acquisition and transfer of the control of variables strategy. Child Development 70, 1098-1120. 
[3] Ha, V., Inkpen, K., Whalen, T., and Mandryk, R. 2006. Direct Intentions: The Effects of Input Devices on Collaboration around a Tabletop Display. In Proceedings of Tabletop ’06 (Mawson Lakes, Australia, January 2006). IEEE Press, 177-184.

[4] Hornecker, E., Marshall, P., Dalton, N. S., and Rogers, Y. 2008. Collaboration and interference: awareness with mice or touch input. In Proceedings of CSCW 2008 (San Diego, CA, November 2008). ACM Press, 167-176.

[5] Inkpen, K., McGrenere, J., Booth, K.S., and Klawe, M. 1997. Turn-Taking Protocols for Mouse-Driven Collaborative Environments. In Proceedings of Graphics Interface '97, (Kelowna, BC, May 1997), 138-145.

[6] Klahr, D. \& M. Nigam. 2004. The equivalence of learning paths in early science instruction: effects of direct instruction and discovery learning. Psychological Science 15, 10, 661667 (2004).

[7] Kuhn, D., Amsel, E., and O’Laughlin, M. 1988. The Development of Scientific Thinking Skills. Academic Press, San Diego, CA.

[8] Moher, T. 2006. Embedded Phenomena: Supporting Science Learning with Classroom-sized Distributed Simulations. In Proceedings of CHI 2006 (Montreal, Canada, April 2006), 691-700.

[9] Moher, T., Ding, X., Wiley, J., Conmy, D., Hussain, S., Singh, P., and Srinivasan, V. (2003). Combining Handhelds with a Whole-Class Display to Support the Learning of Scientific Control. In ACM Conference on Human Factors in Computing Systems Extended Abstracts (Ft. Lauderdale, FL, April 2003), 882-883.

[10] National Research Council. 1996. National Science Education Standards. Washington, DC: National Academy Press.
[11] Ritter, S., Anderson, J. R., \& Koedinger, K. R., Corbett, A. 2007. Cognitive Tutor: Applied research in mathematics education. Psychonomic Bulletin \& Review 14, 249-255.

[12] Roschelle, J., and Pea, R. 2002. A walk on the wild side: How wireless handhelds may change CSCL. In Proceedings of CSCL 2002 (Boulder, CO, Jan. 2002). Lawrence Erlbaum: Hillsdale, NJ, 51-60.

[13] Schauble, L. 1996. The development of scientific reasoning in knowledge-rich contexts. Developmental Psychology 32, 102-109.

[14] Slavin, R. 1990. Cooperative Learning: Theory Research and Practice. Allyn and Bacon.

[15] Soloway, E., Guzdial, M., and Hay, K. 1994. LearnerCentered Design: The Challenge for HCI in The 21st Century. interactions 1, 2, 36-48.

[16] Stewart, J., Bederson, B., and Druin, A. 1999. Single display groupware: A model for co-present collaboration. In Proceedings of CHI '99 (Pittsburgh, PA, May 1999), ACM Press, 286-293.

[17] Tsandilas T., Balakrishnan, R. 2005. An evaluation of techniques for reducing spatial interference in single display groupware. In Proceedings European Conference on Computer Supported Cooperative Work (Paris, France, September 2005), 225-245.

[18] U.S. Department of Education, National Center for Education Statistics. 2001. Early Childhood Longitudinal Study, Percentage distribution of teachers' time spent on certain instructional approaches, by program and school type: Fall 1998.

[19] Wilensky, U., and Stroup, W. 2000. Networked Gridlock: Students Enacting Complex Dynamic Phenomena with the HubNet Architecture. In Proceedings of ICLS 2000 (Ann Arbor, MI, June, 2000). Lawrence Erlbaum: Hillsdale, NJ, 282-289. 